\title{
DESAIN SISTEM INFORMASI ADMINISTRASI DAN KEUANGAN PAUD UNTUK MENCAPAI AKREDITASI
}

\author{
Studi Kasus Paud Hudan Cendikia dan Paud Bina Mandiri Malang
}

\author{
Mardiana Andarwati 1), Lita Dwipasari 2) \\ 1) Fakultas Teknologi Informasi-Sistem Inforrnasi, Universitas Merdeka Malang \\ 2) Fakultas Ekonomi-Perbankan Universitas Merdeka Malang \\ Email: aan.ftiku@gmai1.com, lita_dwipasari@yahoo.com
}

\begin{abstract}
Abstrac-In the preparatory process leading to accredited two-ECD is trying to meet the necessary requirements. Minimum requirements have been met and there are other constraints that compliance management standard components and Standard financing. Both of these will be easily met if there is a tool that is able to integrate all the activities that can generate reports quickly, complete and accurate. Data and information is complete and accurate order management requirements can be open, transparent and accountable. In both early childhood education, and financial data management systems are still done manually. On the other hand increasing the number of students themselves. It often makes power and the system

is usually enough to be able to handle it anymore. Information is ofien slow to parents, teachers who are also oflen diflicult to divide the administration section of time because of their time dealing with students becoming more complex. In addition, if there are certain policies relating to finances often take a long time because the data are correctly not all, data is still missing, incorrect calculations and so on. Therefore this activity is to help make the soflware in data management and financial administration of the manual into administrative and financial information systems are computerized and integrated a collaboration of Microsoft Access and Visual Basic with Windows platform. Training and assistance in this activity is also carried out to ensure the success of the use of this software.
\end{abstract}

Keywords : Paud, accreditation, information system

\section{LATAR BELAKANG}

Usia dini mempakan masa emas perkembangan anak. Lonjakan perkembangan anak terjadi hanya pada masa emas ini. Menyadari hai itu, pemerintah (dalam hal ini Departemen Pendidikan Nasional) bempaya untuk memfasilitasi, rnembina, dan mengarahkan masyarakat agar memahami apa, mengapa, dan betapa pentingnya pendidikan anak usia dini dengan membentuk sebuah layanan Pendidikan Anak Usia Dini (PAUD). Menjamurnya PAUD di Indonesia baik yang hanya mempakan KB (Kelompok Bermain) ataupun KB dan TK (Taman Kanak-Kanak) perlu mendapatkan perhatian khusus agar tidak menimbulkan diiema. Dari data Ditjen PMPTK (2012) terdapat 28 juta orang anak usia dini yang harus mendapat pelayanan pendidikan, namun para pendiri PAUD dan pengelolanya harus memiliki kesiapan SDM, sarana dan prasarana yang memenuhi

persyaratan bagi berdirinya sebuah PAUD. BANPNF (Badan Akreditasi Nasional Pendidikan Non Fonnal) bertugas melaksanakan akreditasi terhadap satuan program/pendidikan PAUD. Akreditasi dilakukan untuk menilai kelayakan penyelenggaraan PAUD dan oleh karena itu terdapat instrument untuk menilai kelayakan tersebut. Terdapat delapan komponen standar yang harus dipenuhi untuk dapat terakreditasi yaitu 1) standar isi 2) standar proses 3) standar kompetensi lulusan 4) standar pendidik dan tenaga kependidikan 5) standar sarana dan prasarana 6) standar pengelolaan 7) standar pembiayaan 8) standar penilaian pendidikan (PP RI no. $19 \mathrm{Th}$ 2005.

Berkenaan dengan komponen standar pengelolaan yang dimaksud diatas, PAUD harus melakukan prinsip pengelolaan secara partisipatoris dan menerapkan manajemen berbasis sekolah yang ditunjukkan dengan kemandirian, kemitraan, partisipasi, keterbukaan serta akuntabilitas. Secara lebih rinci standar ini juga memiliki persyaratan PAUD minimal sudah berdiri dua tahun, tidak pemah berhenti ataupun vakum dalam Kegiatan Belajar Mengajar (KBM), kemudian memiliki tutor, dan memiliki gedung sendiri. Sedangkan komponen standar pembiayaan yaitu mensyaratkan adanya pengawasan dan pertanggungjawaban dalam penyelenggaraan dan pengembangan lembaga PAUD. Secara lebih rinci standar ini menghendaki laporan keuangan secara berkala dan transparan PAUD memang sedang gencar didorong pemerintah untuk terakreditasi bahkan pemerintah berkeinginan PAUD terakreditasi secara international. Namun saat ini masih banyak PAUD yang belum terakreditasi dimana hal ini tidak seimbang dengan pertumbuhan PAUD yang 
semakin menjamur. Memang tidaklah mudah untuk dapat menjadi PAUD yang terakreditasi, oleh karena itu dibutuhkan dukungan dan bantuan dari banyak pihak untuk mendukung tercapainya keadaan tersebut, termasuk perguruan tinggi yang memiliki tenaga dan kemampuan tehnologi serta pengalaman mengenai akreditasi. PAUD yang potensial tidak terlepas dari kendala dimana semua data kesiswaan dan laporan keuangan dilakukan secara manual dan oleh salah seorang guru. Akibatnya :

1) pengeluaran dan pemasukan tidak lengkap terlaporkan karena waktunya yang terbagibagi atau data yang hilang karena tidak segera diproses.

2) laporan membutuhkan waktu yang lama sehingga data keuangan tidak segera diketahui dan berdampak pada saat akan mengambil keputusan tentang pembelian sarana bermain, desain seragam, pemberian makanan sehat. 3) lambatnya pemberian data siswa kepada orang tua menjadi mulai terasa seiring dengan peningkatan jumlah siswa yang diperolehnya.

Permasalahan dalam standait pengelolaan adalah dalam pengolahan data belum terintegrasi sehingga pengumpulan informasi yang terkait dengan siswa (data kesiswaan) seperti identitas siswa, jadwal pembelajaran/kegiatan siswa dan dafiar kehadiran siswa dan data gum serta kaiyawan menj adi tidak akurat dan membutuhkan waktu yang lama. Dan permasalahan dalam standart pembiayaan adalah dalam pengolahan administrasi keuangan yang masih manual sehingga menyebabkan timbulnya masalah pemasukan data, pencarian data, dan pembuatan laporan keuangan membutukan waktu yang lama. Masih banyak data

yang hilang,dan kesalahan perhitungan laporan keuangan

\section{METODE PENELITLAN \}

Permasalahan dalam standait pengelolaan adalah dalam pengolahan data belum terintegrasi sehingga pengumpulan informasi yang terkait dengan siswa (data kesiswaan) seperti identitas siswa, jadwal pembelajaran/kegiatan siswa dan dafiar kehadiran siswa dan data gum serta kaiyawan menj adi tidak akurat dan membutuhkan waktu yang lama. Dan permasalahan dalam standart pembiayaan adalah dalam pengolahan administrasi keuangan yang masih manual sehingga menyebabkan timbulnya masalah pemasukan data, pencarian data, dan pembuatan laporan keuangan membutukan waktu yang lama. Masih banyak data yang hilang,dan kesalahan perhitungan laporan keuangan Permasalahan dalam standait pengelolaan adalah dalam pengolahan data belum terintegrasi sehingga pengumpulan informasi yang terkait dengan siswa (data kesiswaan) seperti identitas siswa, jadwal pembelajaran/kegiatan siswa dan dafiar kehadiran siswa dan data guru serta kaiyawan menj adi tidak akurat dan membutuhkan waktu yang lama. Dan permasalahan dalam standart pembiayaan adalah dalam pengolahan administrasi keuangan yang masih manual sehingga menyebabkan timbulnya masalah pemasukan data, pencarian data, dan pembuatan laporan keuangan membutukan waktu yang lama. Masih banyak data yang hilang,dan kesalahan perhitungan laporan keuangan.

Dari latar belakang dan permasalahan di atas maka dilakukan perancangan program sistem informasi terintegrasi untuk sistem informasiadministrasi dan keuangan. Sistem yang dirancang menggunakan kolaborasi antara Microsoft Access dan Visual Basic. Microsoft Acces yang mempakan kolaborasi editor dan data base yang mudah diimplementasikan di platform Excel yaitu sistem operasi yang umum digunakan oleh kebanyakan masyarakat Indonesia. Dalam pembuatan program aplikasi software sistem informasi untuk informasi administrasi yang terintegrasi. Sistem ini menggunakan program Microsoft Access dan akan menghasilkan laporan kesiswaan, laporan data kelas, laporan tentang guru, laporan tentang karyawan. Aplikasi software sistem administrasi keuangan terintegrasi. Software ini dirancang dengan program Visual Basic. Sistem ini akan menghasilkan laporan Arus kas (cash flow) yaitu untuk kas masuk (cash in), kas keluar (cash out), Rugi laba dan Neraca.

Langkah-langkah pembuatan program administrasi dan keuangan PAUD:

Tahap I. Rencana Pengumpulan Data (data siswa, data kelas data guru dan data karyawan

Tahap Perancangan sistem

a. Rencana Sistem informasi administrasi

Pembuatan data flow dengan diagram sesuai alur proses IPO (INPUT PROSES OUT PUT). Proses Tersebut dapat dilihat pada Tabel 1.

\begin{tabular}{|l|c|c|}
\multicolumn{1}{|c|}{ Tabel 1. IPO Perancangan Sistem } \\
\hline INPUT & \multicolumn{1}{c|}{ PROSES } & OUTPUT \\
\hline Data Kesiswaan & Coding (pemberian kode) & Laporan data siswa \\
\hline Data Kelas & & Laporan data kelas \\
\hline Data guru & & Laporan data guru \\
\hline Data karyawan & & Laporan data karyawan \\
\hline
\end{tabular}

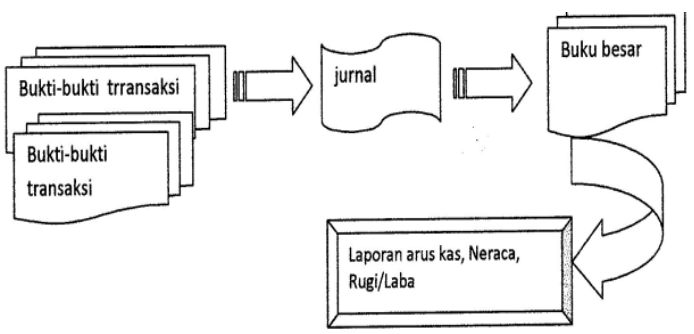

Gambar 1.Perancangan sistem informasi keuangan 


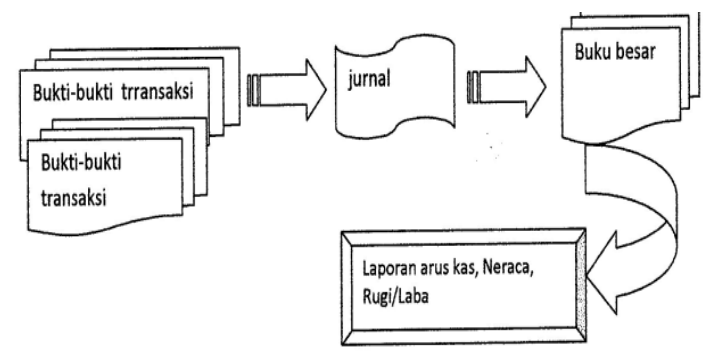

Gambar 1.Perancangan sistem informasi keuangan

Kas masuk yang sudah mtin seperti SPP, Uang Pangkal diinput dikolom pembayaran sebagai penerimaan tetap sedangkan kolom penerimaan adalah mencatat penefimaan yang bersifat sidental atau diluar jenis pembayaran yang telah ditentukan sebagai penerimaan tidak tetap. Pengeluaran adalah mencatat semua transaksi pengeluaran kas, baik pengeluaran tetap maupun tidak tetap.Dalam hal ini terdapat filterberdasarkan jenis pembayarannya dan karyawan tetap/honorer).

\section{HASIL DAN PEMBAHASAN}

Pembuatan sistem infonnasi administrasi dan keuangan PAUD

A.. Sistem Informasi Administrasi

Konteks diagram

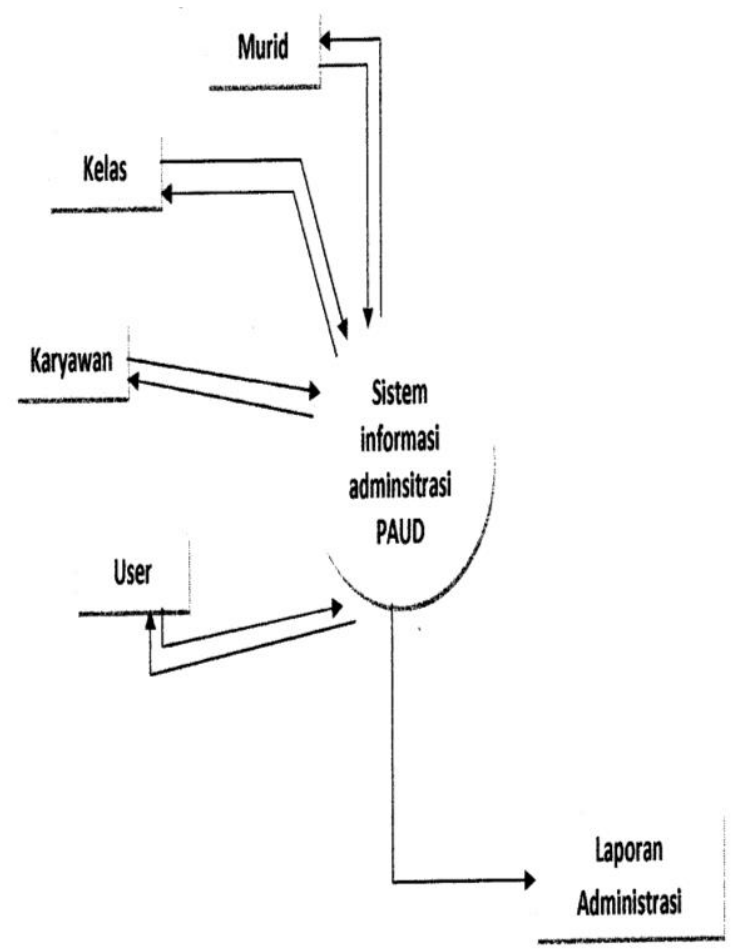

Gambar 3 Konteks Diagram Sistem Informasi PAUD
Tahap I. Pengumpulan data (sebagai input data) a. Data siswa (mengumpulkan data identitas murid play group, TK.A, dan TK. B diPAUD Hudan Cendikia dan PAUD Bina Mandiri) b. Data kelas (mengumpulkan data kelas play group (PG-A dan PG-B); TK.A (TK. A- dan TK.B-2); dan TK.B (TK.B-1 dan TK.B-2)

c. Data guru dan data kalyawan (mengumpulkan data identitas guru tetap/honorer dan karyawan tetap/honorer)

Tahap II. Perancangan (desain) sistem informasi adminsitrasi

Desain sistem infonnasi administrasi PAUD (Pendidikan Anak Usia Dini) yang meliputi

Statement of Purpose (SOP)

Sistem database admiinistrasi PAUD dibuat bertujuan:

a. sebagai sarana agar mudah dalam inelakukan pengelolaan akademik yaitu data siswa data karyawan, dan data user b. mempermudah manaj emen dalam pembuatan laporan adminsitrasi meliputi laporan siswa per kelas, laporan pemasukan harian, dan laporan pengeluaran harian.

Data Flow Diagram (DFD)

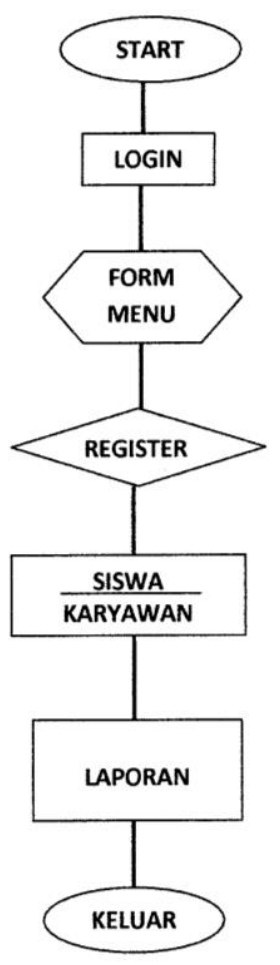

Gambar 4. DFD Sistem Informasi PAUD 


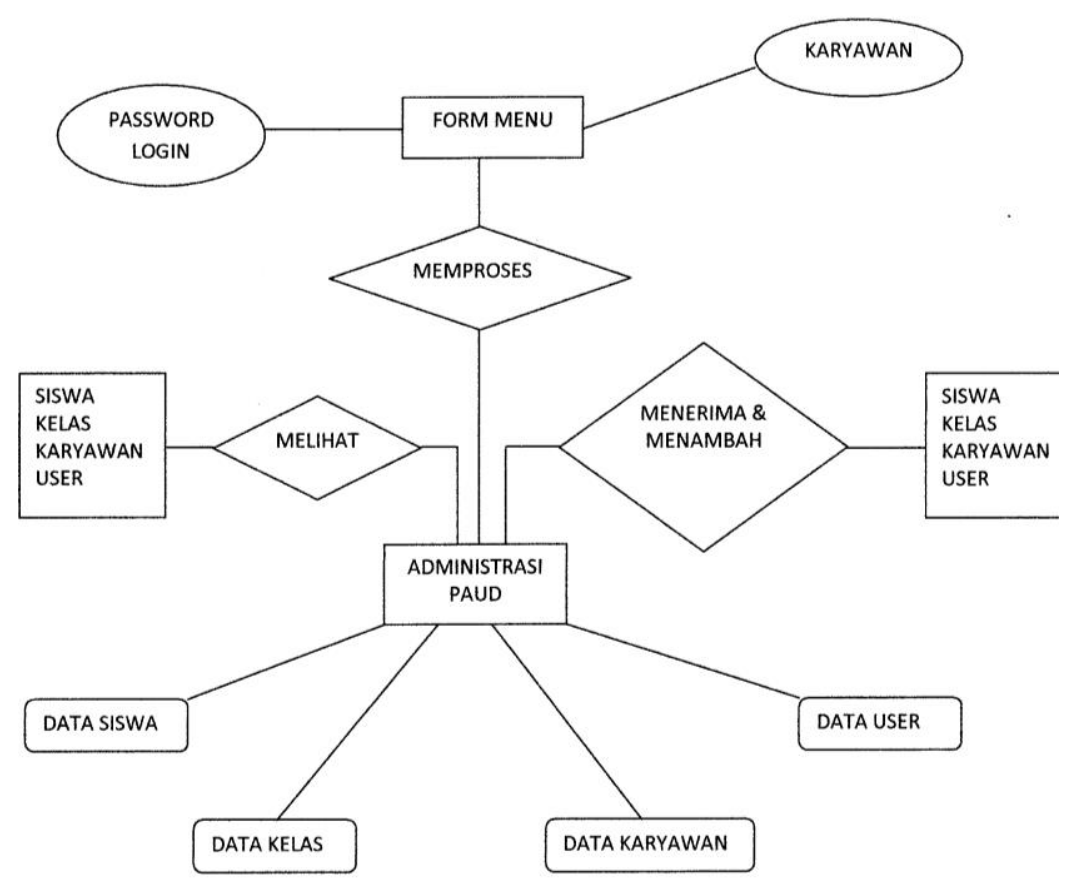

Gambar 5. ERD Sistem Administrasi PAUD

Konteks Diagram Keuangan PAUD

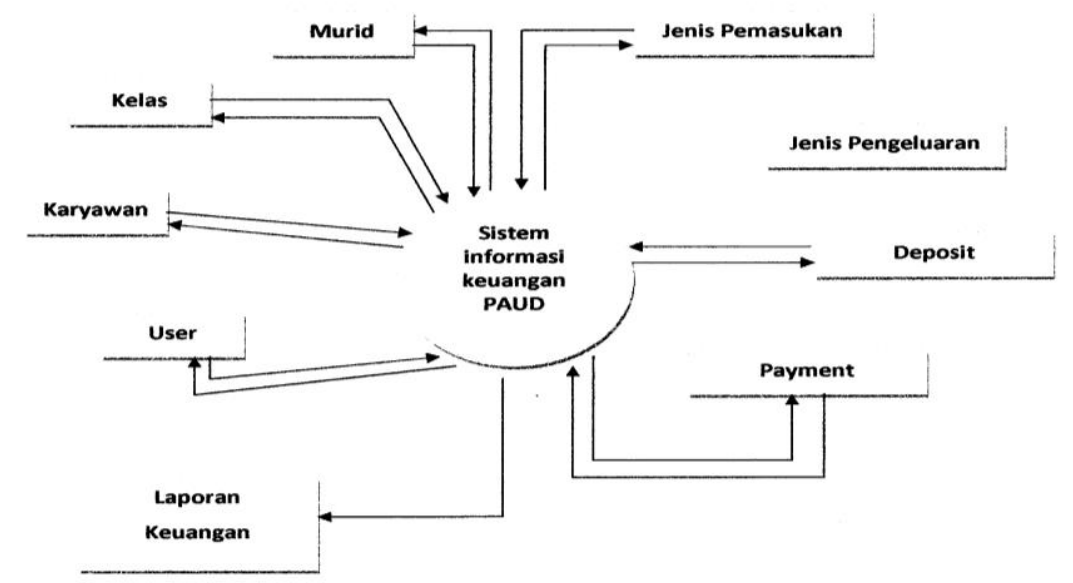

B. Sistem Informasi Keuangan

Gambar 6. Konteks Diagram Sistem Keuangan PAUD

Tahap I. Pengumpulan data (sebagai input data) a. Data transaksi pemasukan keuangan (bukti kwitansi dana pembangunan/DP, SPP, ekstrakulikuler, subsidi/bantuan/sumbangan) b. Data transaksi pengeluaran keuangan (gaji/honor guru/karyawan, air, listrik, telepon, peralatan dan perlengkapan ATK, dan lainnya sesuai kebutuhan)

Tahap II. Perancangan (desain) sistem informasi keuangan

Desain sistern infonnasi keuangan PAUD (Pendidikan Anak Usia Dini) yang meliputi tatement of Purpose (SOP)

Sistem database keuangan PAUD dibuat bertujuan a. sebagai sarana agar mudah dalam melakukan pengelolaan keuangan yaitu data jenis pemasukan dan data jenis pengeluaran

b. sebagai sarana agar mudah dalam melakukan pengelompokkan transaksi pemasukan dan transaksi pengeluaran

c. mempennudah manajemen dalam pembuatan laporan keuangan. Sedangkan laporan keuangan meliputi laporan pemasukan per periode, laporan pengeluaran per periode, laporan pemasukan, dan laporan pengeluaran 


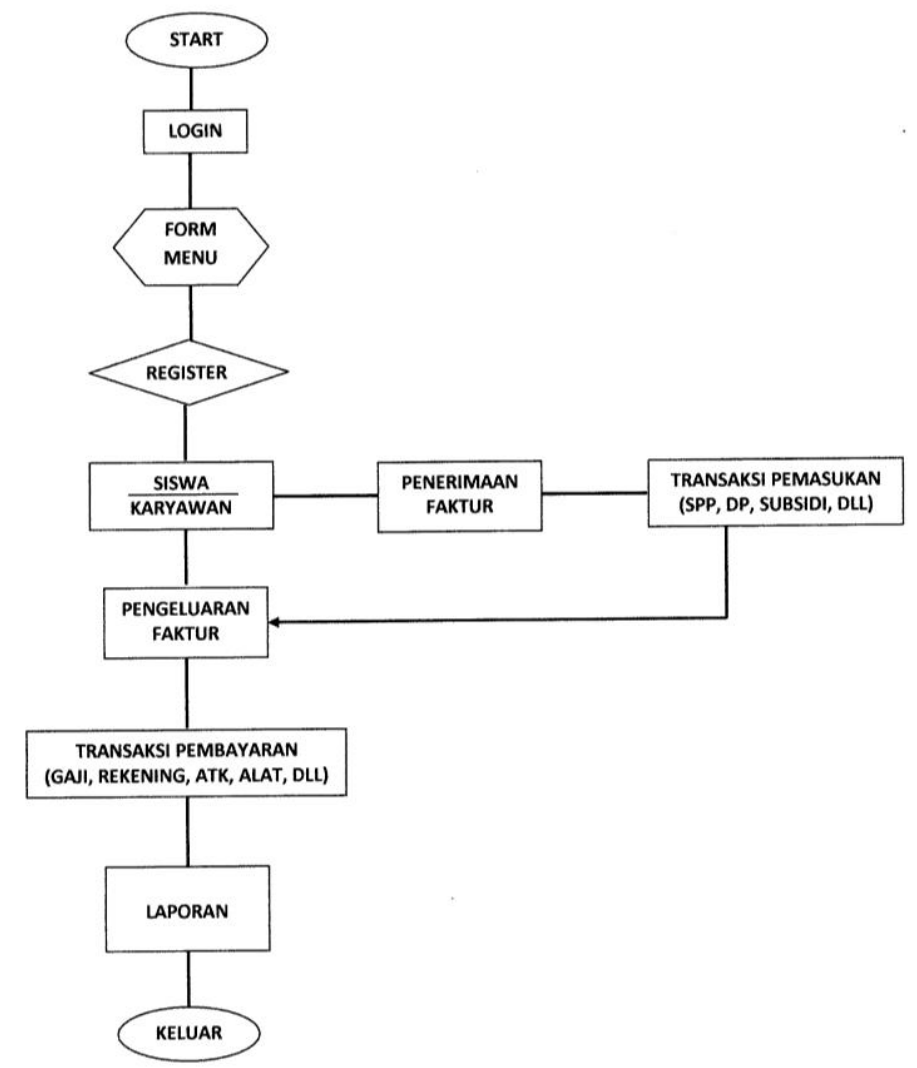

Gambar 7. DFD Sistem Informasi Keuangan PAUD

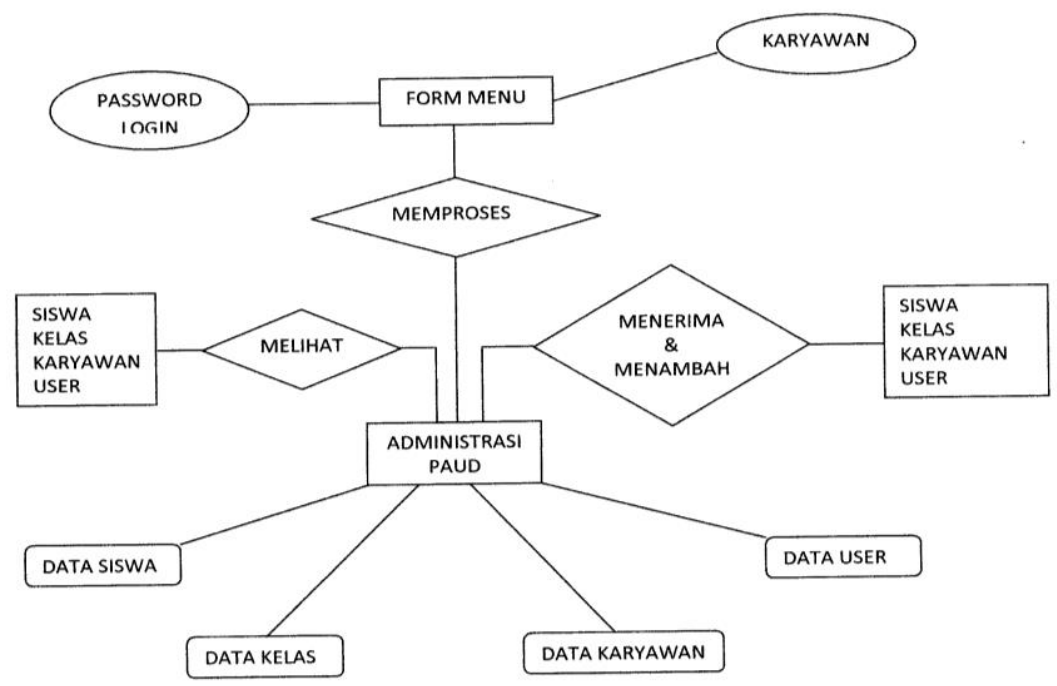

Gambar 8. ERD Keuangan PAUD

3.2.3. Tahap III. Tampilan Progam (perangkat lunak)

Pembuatan program disesuaikan dengan kondisi kebutuhan masing-masing sekolah PAUD. Pada PAUD Bina Mandiri, program yang dibuat lebih sederhana daripada PAUD Hudan Cendikia karena di sekolah PAUD Bina Mandiri jumlah personil yang menangani administrasi dan keuangan PAUD adalah kepala sekolah yang sekaligus sebagai pengelola paud. PAUD Hudan Cendikia pembuatan programnya lebih spesifik yaitu dipilah menjadi menu administrasi, keuangan, dan laporan karena stafi' yang mengoperasionalkan berbeda-beda. Ada staf yang bertugas mengelola administrasi (data siswa, data kelas, data karyawan), mengelola keuangan (transaksi pemasukan dan pengeluaran). Dalam program PAUD, kondisi ini dibedakan dengan adanya fasilitas User Login diawal eksekusi program yang diterapkan pada administrasi PAUD Hudan Cendikia dan pemilahan menu sesuai kewenangan yang diberikan (administrasi dan keuangan). Form keuangan mempunyai empat menu yaitu data jenis pemasukan, data jenis pengeluaran, transaksi pemasukan, dan transaksi 
pengeluaran. Data jenis pemasukan dan data jenis pengeluaran berfungsi untuk entry jenis pemasukan (cash in) dan pengeluaran (cash om). Sedangkan transaksi pemasukan dan transaksi pengeluaran dipergunakan untuk entry transaksi

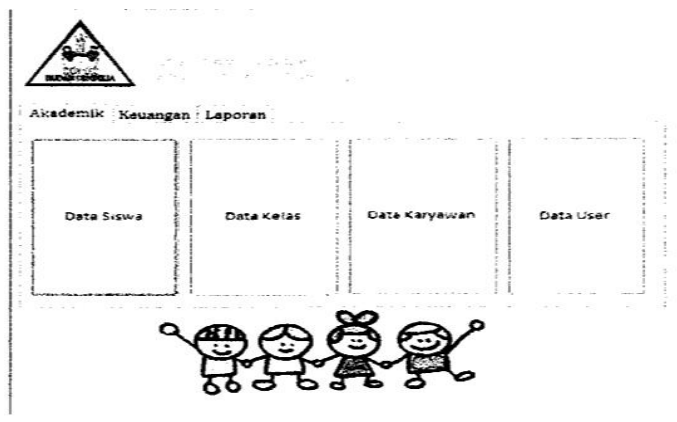

Gambar 9. Form Akademik

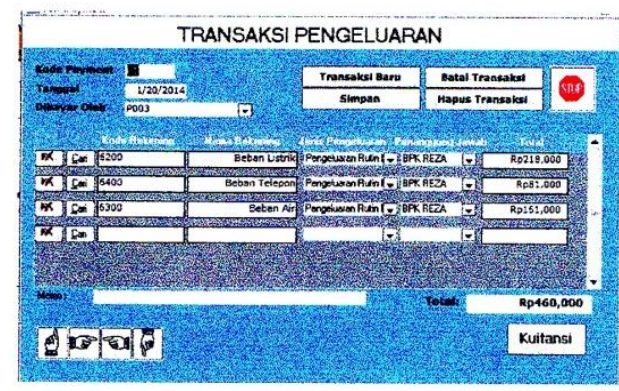

Gambar 11. Tampilan Transaksi Pengeluaran

IV Kesimpulan

Kegiatan dalam peningkatan kualitas sekolah pendidikan anak usia dini non formal menuju akreditasi dilakukan mulai dari desain sistem informasi administrasi keuangan PAUD dan pembuatan program administrasi keuangan PAUD untuk Paud Hudan Cendikia dan Paud Bina Mandiri. Program tersebut dipergunakan untuk sekolah paud yang ingin membawa sekolabnya menuju sekolah yang berkualitas dan bennutu yaitu sekolah paud menuju akreditasi.

\section{DAFTAR PUSTAKA}

[1] Atmoko, Eko. 2013. Program Akuntansi

Beserta Manajemen Aset menggunakan VB dan SQL server. Alex Media Komputindo yang telah. dilakuka PAUD yang disesuaikan dengan jenis pemasukan dan pengeluaran sebelumnya. Tampilan program tersebut dapat dilihat pada Gambar10-12.

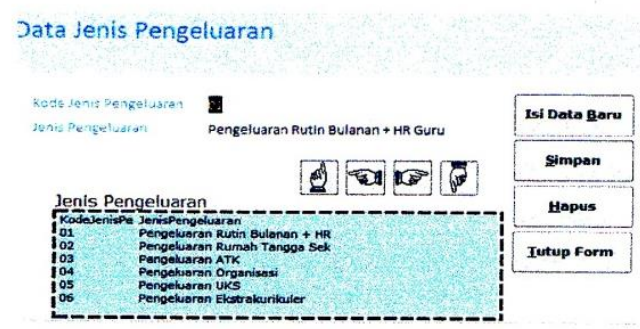

Gambar 10. Tampilan Data Jenis Pengeluaran

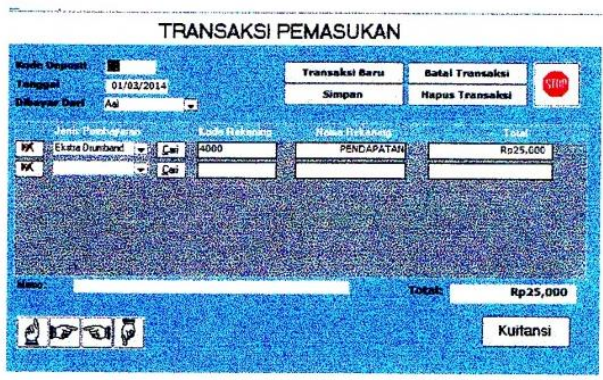

Gambar 12. Tampilan Transaksi

[2] BAN Pendidikan Anak Usia Dini.2009. Instrumen Akreditasi Lembaga PAUD. Hasan, Maimunah.2009. Pendidikan anak Usia Dini. Diva Press.

[3] Jogiyanto HM.2005. Analisi dan desain Sistem Informasi : Pendekatan terstmktur Teori dan Praktek. Aplikasi Bisnis. Yogyakarra. Andi Offset.

[4] Ladjamudin, Al Bahra Bin. 2005. Analisis Dan Desain Sistem Informasi, Yogyakarta: Graha Ilmu.

[5] Marlinda, Linda. 2004. Sistem Basis Data. Edisi 1 Y0gyakarta.. Andi Offset Suzie.2012. Perkembangan Anak Usia Dini (PAUD). Alex Media Komputindo 